\title{
Reflections on the Introduction of Quantitative Assessment in Persuasive Writing Classes
}

\author{
Paul H. Grawe \\ institute for Travesty, Comedy, and Humor Studies and Winona State University, pgrawe@hbci.com \\ Robin J. Grawe \\ Institute for Travesty, Comedy, and Humor Studies, ragrawe@hbci.com
}

Follow this and additional works at: https://digitalcommons.usf.edu/numeracy

Part of the Rhetoric Commons

\section{Recommended Citation}

Grawe, Paul H., and Robin J. Grawe. "Reflections on the Introduction of Quantitative Assessment in Persuasive Writing Classes." Numeracy 7, Iss. 1 (2014): Article 5. DOI: http://dx.doi.org/10.5038/ 1936-4660.7.1.5 


\title{
Reflections on the Introduction of Quantitative Assessment in Persuasive Writing Classes
}

\begin{abstract}
If quantitative reasoning is to be a legitimate part of composition curricula, it must be seen as a valuable tool for composition instructors to use in exploring their own subject. Composition instructors must see the relevance of QR not merely to their students in other subject areas but also directly in their literary and rhetorical studies and careers. Here we reflect on a highly successful program of using quantitative techniques in teaching advanced levels of professional rhetoric, namely persuasive speech and writing. We recount our 15-year experience of running an in-class, empirical and progressive experiment in group negotiations, the Legislative Simulation (LS). The LS provided statistically significant results, some eyeopening, reported in various publications, but here our reflections concern what such an experiment tells us about opportunities and challenges of using quantitative techniques for the improvement of teaching rhetoric in and for itself. It is clear from our experience that QR takes on a somewhat different appearance within the humanities requiring adjustments in pedagogy and expectations. None of the challenges, however, are insuperable, and the rewards for the discipline as well as for a quantitatively competent university are very great.
\end{abstract}

\section{Keywords}

quantitative; measurement; rhetoric; negotiation; humanities; persuasion

\section{Creative Commons License}

\section{c) (7) (8)}

This work is licensed under a Creative Commons Attribution-Noncommercial 4.0 License

\section{Cover Page Footnote}

Paul Grawe is the Program Director of the Institute for Travesty, Comedy, and Humor Studies and Professor of English at Winona State University. He has been involved in assessing various aspects of quantitative reasoning in an across-the-curriculum WSU institutional study of student critical thinking practices.

Robin Grawe is the Executive Director of the Institute for Travesty comedy and Humor Studies. She has investigated numeracy variables in an institutional study of faculty and student critical thinking agendas. She has also extended quantitative reasoning techniques in humanistic approaches to the study of humor. 


\section{Introduction}

There is no reason to think that writing, communication, speech, and the like were not old disciplines when Aristotle wrote his Rhetoric 2300 years ago. There is very great reason to think that Aristotle didn't use quantitative pedagogical techniques with his students and similarly that Roman instructors of the trivium and quadrivium-both strongly centered in rhetoric-didn't bother with quantitative pedagogy either. Things hadn't changed much at all fifteen hundred years later when William Shakespeare and Francis Bacon went to school.

It should thus come as no surprise that teachers of writing today are not typically sensitized to the need, much less the usefulness, of introducing quantitative concerns in their classrooms. Realistically, the teaching of writing may well be the last academic frontier of quantification. Other disciplines - math and the sciences, economics and the other social sciences - these are the disciplines that use math. But professors in language and literature tend to think they have more than enough to do without quantification, thank you.

The underlying premise therein is that, in writing and communication pedagogy, there is no inherent need for quantification. It is at best another "service" that literature professors, dragooned into teaching students to communicate, can give to the university as a whole.

If service to the university is the only enticement, we can expect rhetoric to remain on the frontier of quantitative pedagogy.

While it is certainly a service to the entire university that writing courses emphasize good command of basic numeracy issues, the discussion herein proceeds from the opposite premise: numeracy can provide motivation and even new important discovery for technical writing, which might more accurately be called persuasive writing for professionals. When numeracy is presented to writing departments as yet another service burden, it cannot be surprising if cooperation is half-hearted at best. On the other hand, when numeracy can be presented as serving central teaching goals of all good writing instruction, there is no limit to what the creativity of talented writing teachers can accomplish.

This paper provides a number of perspectives developed from reflections on an inclass technical writing experiment, carried on for well over a decade, inspiring students and fundamentally changing what little had been previously understood in rhetorical contexts about group negotiations.

What was actually found through the experiment, very-high-confidence results about how to succeed in group negotiations, will primarily interest those who have a professional interest in being high-caliber practical rhetoricians. But for those who are interested in a numeracy-competent university, our reflection on this experimental process may suggest how teachers of writing can be enthusiastically recruited in the numeracy effort. In our reflection on the intensive use of quantitative techniques in a technical writing context, we are essentially arguing that attention to quantification, especially quantification experiments enlisting students as fellow learners, can pay big dividends for understanding modern rhetorical challenges, whether or not that experimentation is also a service to the greater university. 


\section{The Basic Theoretical Challenge}

From Aristotle onward the teaching of rhetoric has had a consistent presumption that the right technique is per se what the teaching of writing is about. Students have been encouraged to study an eminent model: Aristotle, Cicero, Horace-or for that matter, Jack Kennedy. Do it his way-employ his technique-and success is assured.

But what if the technique worked for Cicero, Horace, or Kennedy not because of the technique's inherent power but because of something about Cicero, Horace, or Kennedy? For example, what if the technique worked for these three because they were men?

Particularly, what if the technique worked for these three because they were men, whereas I am a woman?

Sincere, motivated students of writing always face this problem. And sadly, many sincere, motivated, and talented students have been driven away from writing careers because the techniques they were taught do work for others-but not for them. For these victims of traditional teaching methods, the attempt to learn to be good writers becomes inherently a long process of resisting wrong-headed advice, advice which the students in their own lives have already found not just to be less than successful but, in fact, to be highly prejudicial to any possible success.

Teachers of rhetoric have always known that their advice is not congenial to all students. But with numeracy never at issue in rhetoric classrooms, it was easy to feel that the "right" students were naturally adept at the "right" techniques, and other students were doomed to lesser careers in which rhetorical proficiency or lack thereof could be minimized.

One would think students would rebel. Some in fact have, but as indicated, their rebellion is largely a giving up and a dropping out. We should realize that the typical student has already had twelve or thirteen years of writing instruction before having enough of the basics under control to start thinking about real persuasion. And the vast majority of students by that time have solid mental walls that imprison them within a conception that successful writing is only a matter of executing the basics they have spent so many years learning. Such mental prison walls militate strongly in favor of doing one's best to implement standard prescriptions for successful writing and then deciding that a life of professional communication is simply out of reach.

If we ask too much of such students in persuasive writing, particularly if we ask them to do what hasn't worked for them when they have already given it a good college try in real life, we can only expect that a great many of them will drop out. On the other hand, quantitative results that clearly demonstrate that people like them can succeed with a particular technique repeatedly work to reignite efforts to succeed in writing for persuasive effect.

Students who have attempted to negotiate are often eager to experiment to see what will work for them. As a visiting professor at Augsburg College, Paul one day overheard his students talking before class. The students having been assigned Herb Cohen's You Can Negotiate Anything (Cohen 1982) were urged to discard any advice that seemed not workable for them, while holding on to whatever few ideas they believed could work for them.

"I tried it,” one woman said. "I read the book cover-to-cover and then went out and negotiated $\$ 2,500$ off on a new car.” 
Guess how seriously other students then took reading the text, not for every idea however outlandish it might seem to them, but rather holding on to the ideas that they heard themselves saying, "Yeah, that could work for me!"

\section{The Legislative Simulation as a Teaching Device}

\section{Design and Administration}

The Legislative Simulation is both a classroom exercise and a research investigation, designed to help students discover what works for them and for people like them. As a teaching instrument, it involves students in a host of quantitative reasoning tasks. Small groups of students negotiate a quantitative budget. Students' relative negotiating success is quantitatively ranked. Students quantitatively assess the use of various rhetorical strategies by others. And thus students are knowingly and directly involved in a quantitative study of the effectiveness of various negotiating strategies for group negotiation.

The Legislative Simulation (LS) was first devised as part of a Master's in Leadership seminar at Augsburg College, Minneapolis MN in 1990. The 30 Augsburg participants were typically professionally experienced in negotiation. The pedagogical success of the LS accompanied by enthusiastic student response at Augsburg led to the simulation's yearly inclusion in an advanced Technical Writing course at Winona State University offered by the English Department.

The LS divides students into groups of five (G5's), or four if necessary, and asks them to negotiate a budget of 1000 units of one million each (each unit perhaps thought of as one million dollars) for a state facing a budget crisis, the imaginary state of Minnehaha, which is bordered on the east by Nakomis, on the south by Michemakwa, and on the west by Upper and Lower New Germany. (Humor was incorporated into the simulation from the start, not to diminish the exercise but to enliven it and to reduce tension, particularly among English majors likely to be put off by competition, quantification, and experimentation.)

The budget covers five super-agencies (thus five to a group): Natural Resources, K12 Education, Colleges and Universities, Welfare, and Highways. Since the superagencies, and thus their budgets, vary greatly in size, the option of allocating the same dollar amount to all agencies becomes absurd. Essentially, each student becomes a state legislative floor leader arguing for a super-agency’s budget.

All students are given a general fact sheet outlining the overall budget challenge, including last year's budget, the governor's budget (the governor and legislature are of differing parties), and departmental budget requests. Each student is also given a fact sheet for one of the five super-agencies, representing that student's portfolio. All students are also given a "breaking news" fact sheet concerning all the departments, notably including special departmental needs, major departmental challenges, and recent departmental scandals. All of these fact sheets, then, make up the fact base from which students must negotiate.

Thus students are given the challenge of using qualitative as well as quantitative arguments to defend quantitative decisions, based on both quantitative and qualitative realities. The assurance that grades are not dependent on negotiating success removes some pressure and allows students to do a little experimenting or risk-taking if they wish. 
Students have one class period to present their budget requests to their G5 and the following class session to complete the negotiation and evaluation process. Any group that fails to come to an agreement is given the governor's budget. (We never had a G4 or G5 that preferred to accept the governor's budget to coming up with their own.)

Once the budget agreement has been reached, each participant completes a feedback form assessing the use of various negotiating techniques by members of his/her group: each is asked to identify the two highest users of each of 21 potential negotiation techniques. Questions include, "Who used the power of authority best?" "Who was best humored?" "Who was most serious?" and "Who was harshest to your portfolio?"

Thus, students have had an opportunity to quantitatively evaluate themselves and the others of their group for the use of a variety of negotiating strategies, even before learning the ranking of their performance relative to that of others with the same portfolio.

This immediate, quantitative evaluation process is a far cry from the subjective sense of “Groan! I was awful!” or "Hey, I blew them all away!” which is heavily dependent on personal psychology, mood, or breakfast. And thus when students do learn of the final rankings, they have already made some quantitative evaluations of various negotiators' performance against which to consider the objective measures of effectiveness. They can say, even before seeing the final results, "I think I was really persistent and uncompromising. I wonder if that worked.” Or, "I tried to make people laugh. I wonder if that helped or not."

The simulation administrator then compiles negotiating results by portfolio. Each participant's success is determined in duplicate-bridge fashion by comparing his/her performance to that of others advocating for the same portfolio. Thus someone playing the negotiator for K-12 Education is given a percentage score of the average K-12 portfolio budget allocation.

The percentage scores are then ordered against the other four percentages in the G5. Each participant is ranked first through fifth in his/her negotiating group (Ranks I through $\mathrm{V}$ ) based on his/her budget allocation expressed as a percentage of the average allocation for that portfolio in all G5's of that simulation session. Thus, if someone representing K12 Education received an allocation of $120 \%$ of the average K-12 allocation, that person ranked higher than the same G5's Highways representative whose allocation was 110\% of the average Highways allocation. Each group will have four or five ranks represented, (Rank III, by a priori rule, is omitted in the case of a G4 with four participants).

Thus before the session is over, each student is ranked I through V within his/her G5 or G4, and thus receives quantitative feedback on his/her negotiating performance based entirely on the quantitative negotiated decisions of classmates.

\section{Immediate Practical Benefits to Students}

The LS quantitative results provide something a professor cannot: a professor can comment on the presumed effectiveness of particular negotiating strategies, whereas the LS provides feedback on the actual result. The student can say, "I went by the book, and it worked!" or "I went by the book, and it didn't work!" or "I went outside the box, and it paid off."

Such immediate feedback to students makes apparent that not all negotiating

techniques work the same way for all negotiators. Perhaps older negotiators can use 
certain techniques which are ineffective for younger negotiators. Perhaps female negotiators can use certain techniques that backfire when used by male negotiators. Students taking the Legislative Simulation were urged to see that such possibilities might alter successful strategies. When quantitative results of the LS were used as feedback, students were the first to find out what they themselves had demonstrated: negotiation techniques' success is highly dependent on the type of person who uses the technique. Thus the LS proved to be a highly effective device for the teaching of persuasion itself.

As for teaching quantitative reasoning, the Legislative Simulation was so intensively quantitative that it guaranteed students would come out with a higher level of quantitative sophistication and competence. That should have been good news to all of their math, economics, and science professors. The good news for language and literature professors was that formerly at-risk students were "seeing the light," turned on to rhetoric in ways that worked for them, and turned on to using their own life experience as real guidance for high-performance persuasive writing.

In retrospect, the gratification of seeing students more willing to investigate how to write well as an on-going, life-long adventure was in itself entire justification for all the quantification efforts employed.

\section{Reflections on Quantification in the Humanities}

\section{Field-Specific Insights}

Our first reflection from this experience on the introduction of quantification in the teaching of rhetoric is that quantification can be valued in the humanities primarily for its value to the humanities; that is, it will be valued according to primarily field-specific concerns in the humanities. Our results, being quantitative, are not naturally user-friendly among rhetoric professors. But even as quantitative results, if these results can be translated into the concerns of people in rhetoric, then writing teachers can be convinced to listen and to value the insights. When teachers of rhetoric have been taught to value quantitative insights into rhetoric itself, then numeracy will naturally increase in rhetoric instruction.

The LS as a fifteen-year research program yielded numerous high-confidence results, which have been reported in many publications and conferences (Domeier 1998; Grawe, P 1992a, b; Grawe 1997; Grawe and Everding 1995; Grawe, R 1995a, b, c; Grawe, R 1997). Many of these findings were counter-intuitive. And they have monumental implications for the teaching of persuasion.

So we turn now to results because such insights are what can make numeracy a valued addition to the teaching of rhetoric.

Can women become Cicero? As we indicated earlier, the fact that for centuries all the emulated models of rhetoric were male should create real queasiness for contemporary teachers of rhetoric whose classrooms contain a majority of women. Are we teaching women students to be suicidal-ignoring what works for them in a vain attempt to imitate what has worked for men?

At least a preliminary answer was possible from the original 30-student experiment at Augsburg College, all of whom were graduate students, almost all of whom were in mid-career and had substantial rhetorical work responsibilities. 
Good news travels fast. The good news was that for multi-party group negotiations, women can do just as well as men (at least when they comprise somewhat more than a simple majority of the sample). Moreover, looking at 22 separate variables, women seemed to do even better than men at standard-advice rhetorical techniques that can be characterized as Persuasive or Actively Assertive (Grawe, P 1992a). Later administrations of the LS bore out this insight.

Bad news travels just as fast but isn't welcome enough to understand. The bad news was that men didn't do as well in exactly these areas that have been the center of rhetorical training for centuries.

On the other hand, we also identified a subset of techniques which we entitled Facilitation and Humor. These techniques are not traditionally emphasized in the teaching of rhetoric. These turned out to be more successful for men than for women (Grawe, P 1992a).

Viewing results with care. Such results, of course, need to be received with caution. Maybe in the contemporary university where women outnumber men in rhetoric courses, a man facing a majority of women in multi-party negotiation would find his best strategy to be humorous and facilitating. And maybe, unless a man is in such a biased situation, he doesn't need to be a facilitator and doesn't need to be humorous.

But maybe, just maybe, men need to value facilitation and humor more than classical rhetorical pedagogy ever recognized in order to be high-performance practical rhetoricians.

Consider, for example, the often-made argument that traditionally men, as the Good Ole Boys, dominated business by making their deals in highly jocular, good-fellowship settings like men's clubs and golf courses. Perhaps with the help of quantification, more teachers of rhetoric would take it seriously. And perhaps some students who under previously accepted pedagogical assumptions would have fallen by the wayside would instead be challenged to use what they had in fact already learned to value in their own lives.

In rhetoric there are no surefire answers about technique. Technique can be more or less successful based on many variables. Our way of testing, the LS situation itself, is one of those variables. Some other teacher of rhetoric designing his or her own test and administering it his or her own way might get different results.

But at least they are results. They are objective clues. Professional rhetoricians, at work for a full lifetime, are constantly getting feedback that can clue them in on what works for them. They will seldom if ever have nearly the same controlled, quantitative clues students received from the LS. less?

In theory then, LS insights themselves are very powerful. But could students care

\section{Igniting a Fire}

Our second reflection is that quantification in rhetorical studies can, in fact, ignite a fire in students.

We summarize two student responses here. We suggest that such student response to a new teaching technique does not "grow on trees."

A Japanese translation of the LS. In the early 1990s, Winona State University had a fairly large contingent of students from Japan. In 1993 one of Paul's students, David 
Everding, who had been particularly befriended by the WSU Japanese student community and who also had participated in the Legislative Simulation, undertook to administer the simulation with Japanese students. The LS was translated by some of these Japanese students and field-tested on Japanese student groups at WSU. In fall, 1994, Everding as a student studying abroad took the Legislative Simulation to the Minnesota State University campus at Akita, Japan. In Akita, Everding formed five additional negotiation groups for a total of 46 Japanese participants in all-Japanese negotiation groups.

We never imagined that our simulation would ever be translated into a second language. Neither of us ever imagined that the simulation could be used for crosscultural comparison. Neither of us ever tried to enlist or dragoon any student into continuing the research we had begun.

David was honored by Winona State for his work, which also has a special place in the history of the Akita campus. He presented on his findings in professional conference (Grawe and Everding 1995).

From the perspective of quantitative reasoning catching fire in students, it is almost irrelevant what David found from all his work and all the work of a determined coterie of Japanese students. However, from another perspective, what he found was quite significant, a perspective we will return to later in this discussion.

A high school application. Mark Domeier was a senior about to graduate from WSU when he took the Legislative Simulation. When he subsequently was hired to teach English in one of the consolidated districts of south-central Minnesota, New RichlandHarland-Ellendale-Geneva High School (NRHEG), he asked to administer the Legislative Simulation at NRHEG. Paul volunteered our data base and statistical analysis of results.

Domeier's administration of the LS got front-page billing in his local newspaper as having borne out Benjamin Franklin's advocacy of persistence in Poor Richard's Almanac (Anderson 1998), a testimony to the potential for quantitative approaches to the teaching of rhetoric to catch fire.

\section{Power in the Teaching of Writing}

The Ellendale Eagle article sheds a third light on quantification in the teaching of rhetoric: quantification has power, including power in the teaching of writing.

In many ways, the Ellendale paper made the point. Mark's students were practicing what Franklin taught: persistence. Franklin is often given credit for guiding, from behind the scenes, America's primary political documents and for singlehandedly engineering, in public, France's entrance into war against England, thus essentially winning the Revolutionary War. Virtually all histories of his activities as minister to France centrally emphasize his unremitting perseverance in getting France "on the American side."

And yet it is doubtful that this central idea of the greatest rhetorician (as well as scientist and political activist) of his century has made any real impression on the teaching of persuasive writing. In particular, when students are asked to write an essay every two weeks, each essay on a totally different subject, can we as teachers of rhetoric really claim to have made persistence an academic subject at all?

Now compare this jaundiced view of what is routinely taught with what Mark Domeier managed to teach quantitatively to his students and, through the newspaper, managed to heavily reinforce for everyone in the community. Ben Franklin's example 
unfortunately has often been ignored by teachers of rhetoric. But quantitative results from enough investigators like Mark Domeier have power to move the discussion forward.

We submit, then, that the LS has a substantial record of lighting interest in approaching rhetorical issues quantitatively. Again, for all those mathematics, economics, and sciences professors who know what quantification has done for the modern world, this is good news and suggests that all we need to do is to convince teachers in writing courses that quantification can be a tremendous ally for their best work as well.

There remain questions about whether all this is merely theoretical or at best pedagogically successful. After all, committed teachers of persuasion want their students to succeed in life and in careers, not just in their classrooms. Proving to them that numeracy will help them help their students to better lives and careers is the best insurance that teachers of writing will join a quantitative reasoning initiative enthusiastically.

\section{Cynicism and the Need for Qualitative Corroboration}

Our fourth reflection is that people in language and literature are more cynical about quantitative results than people in the sciences. Tell someone in science that combining two chemicals has in four cases out of four blown the researcher out the back wall of the laboratory, and that scientist will with high probability avoid such mixture in his own work.

But typically, people in the humanities want more than numerical demonstration: they want experiential, qualitative corroboration. One of the greatest joys of using quantification in the humanities is to find out that there is real-world professional support for many quantitative insights.

The corroboration of published authorities. Thus, Mark Domeier's result that high school juniors and seniors-just ordinary basically educated Americans still in their teens-can and do identify persistence as key to their negotiating success is a particularly great success in the humanities. It is that special success because it confirms what a very great rhetorician had already found in life and advocated with great force. In the humanities, such cross-confirmation of quantified results and otherwise authoritative experience is immeasurably stronger than quantification by itself.

And here we can see the importance of David Everding's Japanese results. When David took Technical Writing, one of the texts was, again, the negotiation classic, You Can Negotiate Anything (Cohen 1982). Cohen is a world-famous international negotiator. In the book, he tells the story of the first time he was let out of the country to negotiate for a client. He was sent to Japan. And as he hilariously relates his adventures, he negotiated so poorly that ever after his firm labeled his efforts "The Second Pearl Harbor.”

It turned out from David's data that the Japanese did not negotiate exactly like Americans. As a matter of fact, they, the Japanese and particularly male Japanese, seemed to prefer "hard-ball" techniques and "hard-ball" results that Americans seem willing to soften. For those who have read Cohen and his hilarious story, David's quantitative results seem to have a consistent base in reality. And again, cross- 
confirmation with a recognized authority of expert experience is immeasurably more impressive than David's quantitative findings by themselves.

Other corroboration from subjective, experiential authority. We once gave coordinated presentations to a seminar on humor and politics at an International Society of Humor Studies conference. Robin's half was about differences in rhetorical success between men and women.

As already mentioned, one of those results was that women are less successful with humor. Another is that they are more successful with what we call OPU (Outspokenness, Persistence, being Uncompromising (Grawe, R 1995c).

In the question-and-answer period, one woman in the audience indicated that the results "weren't fair." Robin tried to parry using the best techniques indicated by quantitative research. The woman repeated more loudly that the results "just weren't fair.” It was an awkward five minutes to say the least. Realistically, quantitative results are not always happily received and may even be dismissed or scorned because of their uncongeniality.

At the end of the session, another woman in the audience came up to Paul, obviously somewhat embarrassed and wanting to make some amends. She did so by saying that she had found the talks very interesting and that "her father" had always "said the same thing” about what worked rhetorically.

Grateful for any support, Paul asked her father's name. He turned out to be a former prime minister of Israel.

Confirmation from non-quantitative sources -in real life, in authoritative sources, in professional anecdote, in literature, in history-is critical to humanistic incorporation of quantitative approaches.

If the humanities are to make use of statistical experiments in their own classrooms, they inevitably must confront the problem of extremely dirty data. In the humanities, it is almost inconceivable to control for a host of human variables in any in-class investigation. It is almost inconceivable, for example, even to ask that every participant in an experiment to have a high-protein breakfast beforehand. Or that they have had previous composition courses that are all close equivalents of one another. The list of such uncontrolled variables is, if not infinitely long, at least much too long for serious consideration.

But with large enough sample sizes, humanities data can yield high-confidence results. Even so, it will take the humanities much longer to appreciate quantitative results given the largely uncontrolled nature of such experiments.

The reason is not that humanities people are troglodytes who can't be made to be interested in statistical results. The reason is that there are so many more variables which humanities explorations cannot control for.

\section{Quantification Adapted for the Humanities}

A fifth reflection then is that quantification looks somewhat different in the humanities and finally must be taught somewhat differently.

Arguments in the humanities typically can't rely solely on quantified results alone, even extraordinarily high-confidence results. There are too many ways for the quantification to be misleading or just plain wrong. If nothing else, since we all live in 
the human condition, even the most extraordinary numerical result routinely comes up against the only-too-human objection, "It's just not fair."

Instead, as this essay attests, in the humanities, quantification arguments must go hand in hand with other kinds of proof: anecdotal evidence, historical precedent, expert opinion in similar circumstances, personal at-risk experience, even a tellingly humorous formulation, and the like.

Humanities can't teach the same kinds of “objective” results that may be possible in the sciences or even perhaps in the social sciences. Instead, with so many uncontrollable variables in back of all our attempts to quantify, we in the humanities routinely work with clues, not facts, about what really makes humans tick and what really is at stake when humans interact.

Numeracy, however, does have the ability to offer us in the humanities some very real clues.

\section{Conclusion: What Is Measured Is What Is Valued}

The President of Winona State during the administration of the Legislative Simulation was Darrell Krueger. A political scientist, President Krueger came to WSU preaching, "What is measured is what is valued."

In the legislature, what is measured is what is valued. It is the same in business. It is the same in sports.

If teachers of rhetoric finally cannot bring themselves to work with the reality of numerical goals, they can't fully prepare their students for careers in which their writing and communication generally are largely objectified and quantified as business success or failure.

But let's remember that teachers of writing have always been in the business of teaching people to think.

So it should be a small step to get instructors of writing to care about their students' using numbers well. (Actually, we can't remember a time when this hasn't been a concern for language professionals.) What is still missing today is convincing teachers of writing that numeracy is for them, not against them, a great tool for them, not a tool for others to use to ask them to bear more of the "service burden" of the university.

\section{Acknowledgments}

We are indebted to Augsburg College and NRHEG High School and to the entire faculty and student body of WSU, to the Bush Foundation, and to President Darrell Krueger, in whose tenure the Legislative Simulation came to life.

\section{References}

Anderson, C. 1998. Persistence pays for Senior Class at NRHEG. Ellendale Eagle. 1998 April 30:1 (col.1).

Cohen, H. 1982. You Can Negotiate Anything. New York: Random House Publishing Group. 
Domeier, M. 1998. Developmental stages in negotiation humor. Humor Quotient Newsletter 4 (2): Article 2. http://www.itchs.org/HQN\%204.2.htm (accessed March 24, 2013).

Grawe, P. 1992a. Variables affecting persuasiveness in negotiation. Fifth Annual Midlands Conference on Language and Literature.

- - 1992b. Can taking a joke breed negotiation success? Tenth International Conference on Humor and Laughter Sixth Annual Midlands conference on Language and Literature 1993.

— - and David Everding. 1995. Toward a culture-specific rhetoric: The United States and Japan. Eighth Annual Midlands Conference on Language and Literature. Good Humor and Negotiation Success. Humor Quotient Newsletter 2 (2): Article 1. http://www.itchs.org/HQN\%202.2.htm (accessed October 19, 1013).

- 1997. Surviving negotiation with Humor: Part II-International Differences. Eighth International Society for Humor Studies Conference.

Grawe, R. 1995a. Humor as negotiation technique: Gender differences. Humor Quotient Newsletter 1 (2): Article 2. http://www.itchs.org/HQN\%201.2.htm (accessed October 19, 2013).

—. 1995b Continuations in humor as negotiation technique: Gender differences. Humor Quotient Newsletter 1 (3) Article 1. http://www.itchs.org/HQN\%201.3.htm (accessed October 19, 2013).

—. 1995c. Small group negotiating: What works for women? Winona Area Women in Business.

— 1997. Surviving negotiation with humor: Part I—Gender differences. Eighth International Society for Humor Studies Conference. 